\title{
The anti-venom potential of Andrographis paniculata (Burm.f.) Nees roots and its constituent skullcapflavone I
}

\author{
Maria Carmen S. Tan ${ }^{1 *}$, Raymond S. Malabed ${ }^{1,2}$, Francisco C. Franco Jr. ${ }^{1}$, Yves Ira A. Reyes ${ }^{1}$, Daisylyn Senna Tan ${ }^{1}$, Glenn G. \\ Oyong $^{3}$, Chien-Chang Shen ${ }^{4}$, Consolacion Y. Ragasa ${ }^{1,5}$ \\ ${ }^{1}$ Chemistry Department, De La Salle University, Manila, Philippines. \\ ${ }^{2}$ Department of Chemistry, Graduate School of Science, Osaka University, 1-1 Machikaneyama, Toyonaka, Osaka, Japan. \\ ${ }^{3}$ Molecular Science Unit Laboratory Center for Natural Science and Environmental Research, De la Salle University, Manila, Philippines. \\ ${ }^{4}$ National Research Institute of Chinese Medicine, Ministry of Health and Welfare, Taipei, Taiwan. \\ ${ }^{5}$ Chemistry Department, De La Salle University Science \& Technology Complex, Biñan City, Philippines.
}

\begin{tabular}{l}
\hline ARTICLE INFO \\
\hline Received on: $27 / 10 / 2018$ \\
Accepted on: 11/01/2019 \\
Available online: $30 / 03 / 2019$ \\
\hline Key words: \\
Andrographis paniculata \\
(Burm.f.) Nees, Naja \\
philippinensis Taylor, gas \\
chromatography-electron \\
ionization-mass spectrometry, \\
secretory phospholipase $\mathrm{A}_{2}$, \\
docking and cluster analysis.
\end{tabular}

\begin{abstract}
The anti-venom activity of Andrographis paniculata (Burm.f.) Nees roots (APR) dichloromethane crude extracts and a promising APR constituent, skullcapflavone I (SKI) was investigated by monitoring the inhibition of secretory phospholipase $\mathrm{A}_{2}\left(\mathrm{sLA}_{2}\right)$ of Naja philippinensis Taylor venom (NPV) crystallized samples. Gas chromatographymass spectrometry was used for the characterization of extracts, while molecular docking was utilized to understand anti-venom properties. Chromatographic analyses primarily revealed the presence of methoxylated flavones. NPV was found to have $\mathrm{SPLA}_{2}$ activity $(0.0796 \pm 0.0018 \mu \mathrm{mol} / \mathrm{minutes} / \mathrm{ml})$ that has been attributed to the poisonous effects. SKI $\left(\mathrm{IC}_{50}: 51.1 \pm 3.5 \mu \mathrm{g} / \mathrm{ml}\right)$, isolated from APR showed strong inhibitory effect on phospholipase activity compared with dichloromethane extracts of APR $\left(\mathrm{IC}_{50}: 192.7 \pm 10.9 \mu \mathrm{g} / \mathrm{ml}\right)$ indicating that SKI was the cause of the bioactivity in APR. Molecular docking simulations showed corresponding results with highly negative binding energies ( -6.59 to $-8.72 \mathrm{kcal} / \mathrm{mol}$ ) predicted for the binding of SKI to PLA, proteins. An important trend found was the presence of free bound $\mathrm{Ca}^{2+}$ lowered binding energies signifying that $\mathrm{Ca}^{2+}$ a has role in the binding of the SKI to PLA proteins. The anti-venom property of APR and the pure compound SKI, upon further studies, could be the first line of defense in the medical protocol of snake venom neutralization.
\end{abstract}

\section{INTRODUCTION}

According to the World Health Organization (by appeal of numerous UN member countries), snake envenomation was listed as the highest priority (Category A) of neglected tropical disease on July 2017 (Chippaux, 2017). It was estimated that 5.4 million snake bites result annually with subsequent $1.8-2.7$ million cases of poisoning (Gutiérrez et al., 2017). Mortality rates due to snake bite poisoning is from 81,410 to 137,880 yearly and the incidence of permanent disabilities and limb amputations are three times as much as morbidity (Gutiérrez et al., 2017). Highly

*Corresponding Author

Maria Carmen S. Tan, De La Salle University, Manila, Philippines. E-mail: maria.carmen.tan@dlsu.edu.ph affected are those in communities where access to medical health care and production of anti-venom immunoglobulins (ASVS) with appropriate immunogens is difficult, especially in marginalized rural areas in low- and middle-income households (Gutiérrez et al., 2017).

Cytotoxins of snake venom comprise nucleases, which hydrolyze and modify the activity of membrane-bound phosphodiester bonds of DNA, phospholipases, and enzymes (Naeem, 2017). The multiplex of venom components is able to depolarize excitable membranes which in turn hydrolyze phosphodiester bonds, heart cells, and neurons which manifests as hemolysis, cytotoxicity, and of disruption of the nervous system (Naeem, 2017). Venom proteases can degrade physiological substrates such as casein, hemoglobin, and fibrinogen which can manifest neurotoxic, myotoxic, cytolytic, edematic, cardiotoxic, 
and anticoagulant effects (Fatima and Fatah, 2014). Short neurotoxin 1 was isolated from and found to be the major lethal component of Naja philippinensis Taylor or the Philippine spitting cobra (Hauert et al., 1974).

Since ASVS is not readily available in all hospitals whether private or public, victims would sometimes require transportation to specific facilities such as the Research Institute of Tropical Medicine (RITM) in the Philippines. In such case, an immediate response is hampered which is essential since neurotoxicity can occur after 60 minutes after incidence depending on the virility and inoculation of envenomation (Brunda and Sashidhar, 2007).

Plant inhibitors of snake venom have been reported to behave as antitoxins in envenomings (Soares et al., 2005). The "king of bitters," Andrographis paniculata (Burm.f.) Nees, has been used for centuries to treat a variety of diseases such as respiratory infections, fever, herpes, sore throat and a variety of other chronic and infectious diseases (Gupta et al., 1990). Its major constituents are diterpenoids, flavonoids, and polyphenols (Chao and Lin, 2010). Our earlier research reported the isolation of 14-deoxy-12-hydroxyandrographolide, 14-deoxyandrographolide, and 14-deoxy-11,12-dihydroandrographolide from the leaves of A. paniculata (Ragasa et al., 2008). We also reported the isolation of andrographolide, 14-deoxyandrographolide, 14-deoxy-12-hydroxyandrographolide, $\beta$-sitosterol, stigmasterol, and chlorophyll a from the leaves; $\beta$-sitosterol, stigmasterol, 5,2'-dihydroxy-7,8-dimethoxyflavone, long chain trans-cinnamate esters, and $\beta$-sitosteryl fatty acid esters from the roots; $\beta$-sitosterol, monogalactosyl diacylglycerols, lupeol, and triacylglycerols from the pods; and 14-deoxyandrographolide from the stems of $A$. paniculata (Tan et al., 2016).

In this work, we established the phospholipase activity of $N$. philippinensis venom and the anti-venom activities of the dichloromethane crude extracts $A$. paniculata roots (APR) and a constituent isolated from APR, skullcapflavone I, or 5,2'-dihydroxy7,8-dimethoxyflavone (SKI), through a commercial phospholipase activity assay kit using crystallized $N$. philippinensis venom. Chemical characterization of the crude extracts was done through gas chromatography-electron ionization-mass spectrometry (GCEI-MS). Molecular docking simulations were performed between SKI to a phospholipase structure (PLA $)$ from Naja sp. acquired from the protein data bank (PDB) to analyze binding affinities and possible stereochemical noncovalent bonding. To the best of our knowledge, this is the first reported study using this methodology of gas chromatographic analyses, secretory phospholipase $\mathrm{A}_{2}$ $\left(\mathrm{sLA}_{2}\right)$ activity, and docking and cluster analyses (PLA with SKI) against the aforementioned venom.

\section{MATERIALS AND METHODS}

\section{Plant material}

Andrographis paniculata family Acanthaceae plants were grown and harvested from Bataan, Philippines. The plant was authenticated at the Botany Division, Philippine National Museum. Venom from $N$. philippinensis Taylor (NPV) in lyophilized (freeze-dried) form was procured from the RITM, Department of Health, Philippines.

\section{Chemical extraction and GC-EI-MS characterization}

The freeze-dried APR ( $3 \mathrm{~g})$ was ground in a blender, soaked in $\mathrm{CH}_{2} \mathrm{Cl}_{2}$ (dichloromethane) for a 24-hour interval, and then filtered to afford crude extracts $(\sim 38 \mathrm{mg})$ after subsequent concentration through the rotary evaporator. The dried extracts were dissolved in $1 \mathrm{ml}$ of DCM for GC-EI-MS analyses. Structures derived were analyzed for peak area from the percent total of the sum of corrected areas. SKI was previously isolated as reported in a prior work (Tan et al., 2016).

An Agilent GC MS 7890B with a HP-5 ms (5\% phenyl methyl siloxane) Ultra Inert column $(30 \mathrm{~m} \times 250 \mathrm{~mm} \times 0.25 \mathrm{~mm})$ with helium as a gas carrier was used for the triplicate analyses of the volatile constituents. The flow rate of the helium gas was set at $1.0587 \mathrm{ml} /$ minutes, pressure was made to be at $9.4889 \mathrm{psi}$, with an average velocity of $37.862 \mathrm{~cm} /$ second and hold time of 1.3206 minutes. The initial set point temperature was at $70^{\circ} \mathrm{C}$. The program was as followed: first ramp was set at $2{ }^{\circ} \mathrm{C} /$ minutes to $135^{\circ} \mathrm{C}$ and held for 10 minutes, second ramp had a rate of $4^{\circ} \mathrm{C} /$ minutes to $220^{\circ} \mathrm{C}$ and held for 10 minutes, and finally, the last ramp had a rate of $3.5^{\circ} \mathrm{C} /$ minutes to $270^{\circ} \mathrm{C}$ and held for 37 minutes.

Compound identification was done using the National Institute of Standards and Technology (NIST) library, 2.0 and peak areas ( $\%$ of total) was processed from the resultant total ion chromatograms. The resultant data were confirmed by the comparison of the compounds according to their elution order with their relative retention indices on a non-polar stationary phase. The retention indices were computed for all the volatile constituents utilzing a homologous series of $n$-alkanes.

\section{sPLA 2 activity of $N$. philippinensis venom}

The secretory phospholipase $\mathrm{A}_{2}\left(\mathrm{sPLA}_{2}\right)$ activity of NPV was assessed using a commercially available kit (Secretory Phospholipase $\mathrm{A}_{2}$ Assay Kit Cat. No. ab133089) purchased from $\mathrm{Abcam}^{\circledR}$ (Cambridge, UK). PLA 2 (EC 3.1.1.4) is responsible for the hydrolysis at the $s n-2$ position of phospholipids producing a lysophospholipid and a free fatty acid. The PLA-induced release of arachidonic acid from membrane phospholipids is believed to have a major role in the control of eicosanoid production in cells.

The components of the assay kit were prepared as indicated by the manufacturer. The kit includes the following: assay buffer (10×), 5,5'-dithio-bis-(2-nitro-benzoic acid) (DTNB), diheptanoyl thio-PC substrate, bee venom (control), and a 96-well polystyrene F-bottom clear microplate (Greener Bio One).

A $25 \mathrm{mM}$ Tris- $\mathrm{HCl}$ containing $10 \mathrm{mM} \mathrm{CaCl} 2,100 \mathrm{mM}$ $\mathrm{KCl}$, and $0.3 \mathrm{mM}$ Triton $\mathrm{X}(\mathrm{pH} 7.5)$ assay buffer was prepared by mixing $3 \mathrm{ml}$ of the concentrate with $27 \mathrm{ml}$ of high performance liquid chromatography (HPLC) grade water. This buffer system (diluted assay buffer) was used to reconstitute the substrate and samples for the assay. Next, a vial of lyophilized DTNB was reconstituted with $1.0 \mathrm{mM}$ of HPLC-grade water to make $10 \mathrm{mM}$ DTNB in $0.4 \mathrm{M}$ Tris- $\mathrm{HCl}(\mathrm{pH} 8.0)$ and was stored in the dark at $0^{\circ} \mathrm{C}$ prior to use. For the diheptanoyl thio-PC buffer, the content of the vial was reconstituted with $12 \mathrm{ml}$ of diluted assay buffer to make a final concentration of $1.66 \mathrm{mM}$. Lastly, bee venom (positive control) was prepared by dissolving an aliquot of bee venom $\mathrm{SPLA}_{2}$ standard with diluted assay buffer, which gives a final concentration of $100 \mu \mathrm{g} / \mathrm{ml}$. Likewise, NPV was dissolved 
in the diluted assay buffer to make a stock solution that gave a final concentration of $100 \mu \mathrm{g} / \mathrm{ml}$. All the sample components were prepared within the day of analysis, under controlled temperature and lighting, to avoid decomposition.

The sPLA $_{2}$ activity of NPV was determined using a colorimetric assay in comparison with bee venom sPLA, (positive control) and non-enzymatic controls (negative control). The components for the assay were carefully pipetted into a 96-well plate. The negative control wells consisted of $10 \mu \mathrm{DTNB}$ and 15 $\mu \mathrm{l}$ assay buffer, while the positive control wells consist of $10 \mu \mathrm{l}$ DTNB, $10 \mu \mathrm{l}$ bee venom PLA 2 (100 $\mu \mathrm{g} / \mathrm{ml}$ final concentration), and $5 \mu \mathrm{l}$ assay buffer. The sample wells consist of $10 \mu \mathrm{l}$ DTNB, $10 \mu \mathrm{l} \mathrm{NPV}(100 \mu \mathrm{g} / \mathrm{ml}$ final concentration), and $5 \mu \mathrm{l}$ assay buffer. The reaction was initiated by adding $200 \mu$ of substrate solution into each well, followed by colorimetric analysis using Corona Electric Multimode Microplate Reader (MTP-800, Corona Electric Co. Ltd., Ibaraki, Japan) at an absorbance of $414 \mathrm{~nm}$. The contents of the plate were homogenized using the mixing function at a medium speed for 5 seconds prior to absorbance reading. The reaction was monitored for a total of 30 minutes with absorbance reading per minute. The total volume per well was $225 \mu \mathrm{l}$ and the measurements were done in the triplicate. A linear increase in the absorbance was observed in the positive control and sample wells. The change in absorbance $\left(\Delta \mathrm{A}_{414}\right)$ per minute was calculated by plotting the absorbance values as a function of time to obtain the rate (slope). Likewise, the rate of $\Delta \mathrm{A}_{414}$ for the negative control was determined and subtracted from that of the positive and sample wells. The sPLA 2 activity for bee venom and NPV were calculated using Eq. (1).

$\operatorname{sPLA}_{2}$ activity ( $\mathrm{mol} /$ minutes $/ \mathrm{ml}$ )

$$
=\frac{\mathrm{A}_{414} / \text { minutes } \times 0.225 \mathrm{ml}}{10.66 \mathrm{mM}^{-1}} \times \frac{\text { Sample dilution }}{0.01 \mathrm{ml}}
$$

\section{Inhibitory $\mathbf{S P L A}$ activity of APR and SKI}

The inhibitory effects of APR and SKI isolated from A. paniculata were, respectively, determined against cobra venom sPLA $_{2}$ using the assay kit described previously. The lyophilized samples were dissolved in methanol or dimethyl sulfoxide (DMSO) to prepare a $100 \mathrm{mg} / \mathrm{ml}$ stock solution. Aliquot portions were dissolved in DMSO to prepare various samples at a final concentration ranging from 1 to $1,000 \mu \mathrm{g} / \mathrm{ml}$.

The negative control wells consist of $5 \mu \mathrm{DMSO}, 10 \mu \mathrm{l}$ DTNB, and $10 \mu \mathrm{l}$ assay buffer, while the positive control wells consist of $5 \mu \mathrm{l}$ DMSO, $10 \mu \mathrm{l}$ DTNB, and $10 \mu \mathrm{l} \mathrm{NPV}(100 \mu \mathrm{g} / \mathrm{ml}$ final concentration). The sPLA 2 activity of $100 \mu \mathrm{g} / \mathrm{ml} \mathrm{NPV}$ was monitored in the presence of the inhibitors APR and SKI. Seven concentrations of plant extracts ranging from 1 to $1,000 \mu \mathrm{g} / \mathrm{ml}$ were tested against $100 \mu \mathrm{g} / \mathrm{ml} \mathrm{NPV}$. The sample wells consisted of $5 \mu \mathrm{l}$ inhibitor in DMSO, $10 \mu \mathrm{l}$ DTNB, and $10 \mu \mathrm{l} \mathrm{NPV}(100 \mu \mathrm{g} / \mathrm{ml}$ final concentration). The reaction was initiated by adding $200 \mu \mathrm{l}$ of substrate solution into each well, followed by colorimetric analysis using Corona Electric Multimode Microplate Reader (MTP-800, Corona Electric Co. Ltd., Ibaraki, Japan) at an absorbance of $414 \mathrm{~nm}$. The inhibitory effect was determined by calculating the sPLA $_{2}$ activity as described earlier using Eq. (1). In addition, the \%inhibition was determined as shown in Eq. (2), based on the calculated $\mathrm{SPLA}_{2}$ activities. The concentration of extracts inducing $50 \%$ inhibition $\left(\mathrm{IC}_{50}\right)$ was also reported.

$$
\begin{aligned}
& \% \text { inhibition }=\frac{X_{\text {CONTROL }}-X_{\text {SAMPLE }}}{X_{\text {CONTROL }}} \times 100 \\
& \begin{aligned}
& X_{\text {CONTROL }}- \text { sPLA } 2 \text { Activity of positive control }(100 \mu \mathrm{g} / 1 \\
& \text { NPV) } \\
& X_{\text {SAMPLE }}- \text { sPLA } 2 \text { Activity in the presence of inhibitor } \\
& \text { (plant extracts) }
\end{aligned}
\end{aligned}
$$

*The absorbance values were corrected against the blank sample (DMSO).

\section{Computational methods}

Several protein candidates which are known to be present in the venom of $N$. philippinensis: phospholipases, neurotoxins, and cardiotoxins were initially screened using Autodock Vina (Trott and Olsen, 2009). Top protein target candidates (PDB IDs: 1LN8, 1S6B, 1PSH, and 1A3F) from the screening were further analyzed using AutoDock 4.0 (Morris et al., 2009). The structure of SKI was docked into the candidates using Lamarkian Genetic Search algorithm. Blind docking was done by defining a grid box that encompasses the entire protein structure for each target. For each target, 200 independent GA runs with a population size of $150,2,500,000$ evaluations, and 27,000 maximum generations. The 200 docking conformations of SKI were scored based on the calculated binding energy and clustered according to the root mean squared deviation for each target generation.

\section{RESULTS AND DISCUSSION}

\section{Characterization of dichloromethane extracts}

GC-EI-MS analyses of the dichloromethane extracts of APR led to the identification of 16 constituents. The identified components of the low-boiling point compounds of the crude extract were substantiated by retention index (RI) and structural class through the NIST library. The results are listed in Table 1 according to their elution order on a HP-5ms column, as visualized on Figure 1. The sample consisted primarily of methoxylated flavones: 5,2'-dihydroxy-7,8-dimethoxyflavone (4.85\%), 4H-1-benzopyran-4-one, 2-(3,4-dimethoxyphenyl)-5,6-dihydroxy-7,8-dimethoxy-(3.21\%), and 4H-1-benzopyran-4-one, 2-(3,4-dimethoxyphenyl)-5-hydroxy-3,6,7-trimethoxy-(0.79\%); a flavonoid glycoside [4H-1-benzopyran-4-one, 7-( $\beta$-D-glucopyranosyloxy)-5-hydroxy-2-(3-hydroxy-4-methoxyphenyl)-] which was the base peak (10.11\%); fatty acids: n-hexadecanoic acid (3.08\%) and 9,12-octadecadienoic acid (Z,Z)- (1.06\%); sterols: androst-4-ene-3,17-dione (0.94\%), stigmasterol (4.51\%), and $\gamma$-sitosterol $(3.08 \%)$; a diarylethene ether, 3,3',4,4'-tetramethoxystilbene (4.91\%); a polyprenol, 1,6,10,14,18,22-tetracosahexaen-3-ol, 2,6,10,15,19,23-hexamethyl-, (all-E)- (1.32\%); a lignan, yangambin $(0.71 \%)$; an aryl isocyanate, 3,5-dimethylphenyl isocyanate $(0.86 \%)$; an alkyl ester, propanoic acid, 2-methyl-, 1-(1,1-dimethylethyl)-2-methyl-1,3-propanediyl ester $(0.35 \%)$; and two constituents with diverse functional groups: benzaldehyde, 4-hydroxy-3,5-dimethoxy-, [(4-hydroxy-3,5-dimethoxyphenyl)methylene]hydrazine $(5.30 \%)$ and $2 \mathrm{H}, 8 \mathrm{H}-$ benzo[1,2-b:5,4-b'] 
Table 1. The chemical composition of APR DCM extracts.

\begin{tabular}{|c|c|c|c|c|c|}
\hline $\begin{array}{c}\text { Peak } \\
\text { number }\end{array}$ & $\begin{array}{c}\text { RT } \\
\text { (minute) } \\
X \pm \text { SD }\end{array}$ & Compound $^{\mathrm{b}}$ & $\mathbf{R I}^{\mathbf{a}}$ & $\%$ peak area & Functionality \\
\hline 1 & $21.10 \pm 0.054$ & 3,5-Dimethylphenyl isocyanate & 1333 & 0.86 & Aryl isocyanate \\
\hline 2 & $36.78 \pm 0.049$ & $\begin{array}{l}\text { Propanoic acid, 2-methyl-, 1-(1,1-dimethylethyl)-2-methyl-1,3- } \\
\text { propanediyl ester }\end{array}$ & 1597 & 0.35 & Alkyl ester \\
\hline 3 & $57.78 \pm 0.074$ & n-Hexadecanoic acid & 1953 & 3.08 & Saturated fatty acid \\
\hline 4 & $61.34 \pm 0.83$ & 9,12-Octadecadienoic acid (Z,Z)- & 2135 & 1.06 & polyunsaturated fatty acid \\
\hline 5 & $74.07 \pm 0.0039$ & $\begin{array}{l}\text { 4H-1-Benzopyran-4-one, 7-( } \beta \text {-D-glucopyranosyloxy)-5-hydroxy-2- } \\
\text { (3-hydroxy-4-methoxyphenyl)- }\end{array}$ & 2524 & 10.11 & Flavonoid glycoside \\
\hline 6 & $75.46 \pm 1.03$ & 3,3',4,4'-Tetramethoxystilbene & 2542 & 4.91 & Diarylethene ether \\
\hline 7 & $81.59 \pm 0.0033$ & 5,2'-Dihydroxy-7,8-dimethoxyflavone & 2748 & 4.85 & Methoxyflavone \\
\hline 8 & $85.52 \pm 0.10$ & Androst-4-ene-3,17-dione, 12-hydroxy-, bis(O-methyloxime), (12 $\beta)$ - & 2893 & 0.94 & Androsterone \\
\hline 9 & $87.40 \pm 0.064$ & $\begin{array}{l}\text { Benzaldehyde, 4-hydroxy-3,5-dimethoxy-, [(4-hydroxy-3,5- } \\
\text { dimethoxyphenyl)methylene]hydrazone }\end{array}$ & 2975 & 5.30 & Diverse functional groups \\
\hline 10 & $88.32 \pm 0.056$ & $\begin{array}{l}\text { 1,6,10,14,18,22-Tetracosahexaen-3-ol, 2,6,10,15,19,23-hexamethyl-, } \\
\text { (all-E)- }\end{array}$ & 3014 & 1.32 & Polyprenol \\
\hline 11 & $92.91 \pm 0.15$ & $\begin{array}{l}\text { 2H,8H-Benzo[1,2-b:5,4-b']dipyran-10-propanoic acid, 5-methoxy- } \\
\text { 2,2,8,8-tetramethyl-, methyl ester }\end{array}$ & 3188 & 1.60 & Diverse functional groups \\
\hline 12 & $94.05 \pm 0.095$ & $\begin{array}{l}\text { 4H-1-Benzopyran-4-one, 2-(3,4-dimethoxyphenyl)-5,6-dihydroxy- } \\
\text { 7,8-dimethoxy- }\end{array}$ & 3222 & 3.21 & Methoxyflavone \\
\hline 13 & $95.53 \pm 0.14$ & Stigmasterol & 3261 & 4.51 & Phytosterol \\
\hline 14 & $95.73 \pm 0.27$ & $\begin{array}{l}\text { 4H-1-Benzopyran-4-one, 2-(3,4-dimethoxyphenyl)-5-hydroxy-3,6,7- } \\
\text { trimethoxy- }\end{array}$ & 3270 & 0.79 & Methoxyflavone \\
\hline 15 & $97.64 \pm 0.16$ & $\gamma$-Sitosterol & 3319 & 3.08 & Phytosterol \\
\hline 16 & $113.62 \pm 0.25$ & Yangambin & 3548 & 0.71 & Furofuran lignan \\
\hline
\end{tabular}

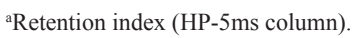

${ }^{\mathrm{b}}$ Compounds listed in order of elution from a HP-5ms column.

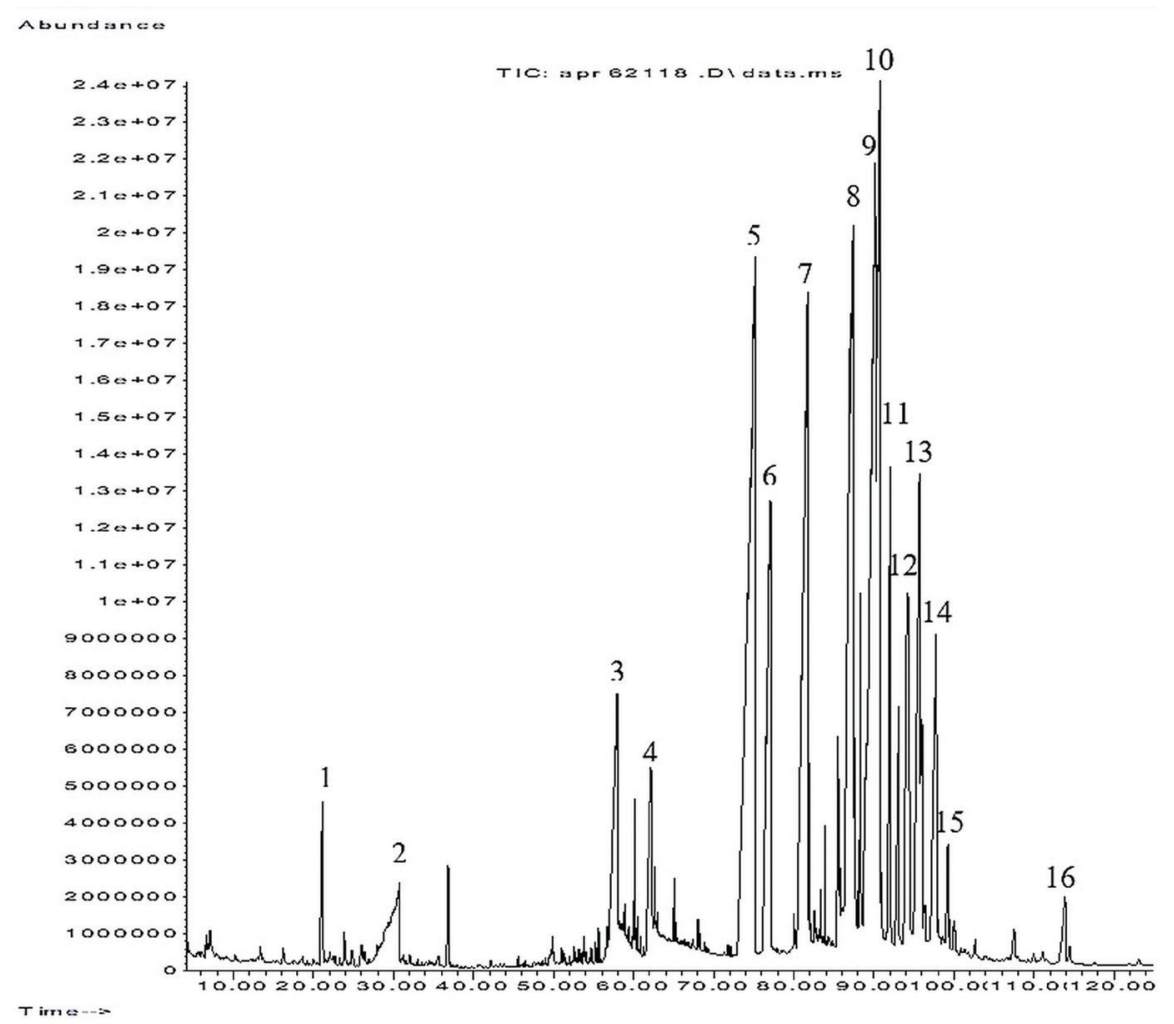

Figure 1. Total ion chromatogram of dichloromethane extract of APR with numbered constituents. 
dipyran-10-propanoic acid, 5-methoxy-2,2,8,8-tetramethyl-, methyl ester (1.60\%).

Hierarchical clustering has been utilized to interpret GCMS data. This was done through calculating the distance matrices of data objects and then merging objects that are close to each other to form sub-clusters (Moon et al., 2009). Further generation of the Figure 2 was facilitated through the clustergram function of MATLAB.

Figure 2 illustrated that androst-4-ene-3,17-dione, 12-hydroxy-, bis(O-methyloxime), (12 $\beta)$ - (8), 1,6,10,14,18,22-tetracosahexaen-3-ol, 2,6,10,15,19,23-hexamethyl-, (all-E)- (10), 2H, 8H-benzo[1,2-b:5,4-b']dipyran-10-propanoic acid, 5-methoxy2,2,8,8-tetramethyl-, methyl ester (11), 4H-1-benzopyran-4-one, 2-(3,4-dimethoxyphenyl)-5-hydroxy-3,6,7-trimethoxy-(14), and $\gamma$-sitosterol (5) formed a distinct cluster with a relatively higher RI and low percent peak area. This indicated that there were small quantities of relatively non-polar components in APR. Another cluster was formed from compounds of diverse functionality. Another segregated group constituted 3,5-dimethylphenyl isocyanate (1), propanoic acid, 2-methyl-, 1-(1,1-dimethylethyl)-2-methyl-1,3-propanediyl ester (2), n-hexadecanoic acid (3), and 9,12-octadecadienoic acid (Z,Z)- (4). 1,2,3,4, which were mostly fatty acids, exhibited the lowest RI and abundance. Lastly, it should be noted that SKI (7), whose chemical structure is seen in Figure 3, was found to be of relatively high abundance in APR.

\section{sPLA 2 activity of $N$. philippinensis venom}

The plot of absorbance values of as a function of time is shown in Figure 4 for both NPV and bee venom. By using Eq. (1), sPLA 2 activity was calculated for bee venom and NPV, which were $0.1074 \pm 0.0031 \mu \mathrm{mol} / \mathrm{minutes} / \mathrm{ml}$ and $0.0796 \pm 0.0018 \mu \mathrm{mol} /$ minutes $/ \mathrm{ml}$, respectively. The results suggested that the $\mathrm{SLA}_{2}$ activity of bee venom is higher than that of NPV. As expected, NPV contains $\mathrm{sPLA}_{2}$, which is typical for venoms extracted from related Naja species (Gopi et al., 2014). However, the amount of sPLA $_{2}$ responsible for the hydrolysis of the substrate cannot be determined directly using this assay. The presence of other proteins in Naja sp. such as neurotoxins, natrin, disintegrin, cholesterinase, and hyaluronidase should also be taken into account.

\section{Inhibitory sPLA activity of APR and SKI}

The sPLA 2 activities in the presence of inhibitors were determined similarly using Eq. (1) and compared with that of NPV in the absence of inhibitors $(0.0837 \pm 0.0017 \mu \mathrm{mol} / \mathrm{minutes} / \mathrm{ml})$. The roots showed the high activity as exhibited by the $\mathrm{IC}_{50}$ value at $192.7 \pm 10.9 \mu \mathrm{g} / \mathrm{ml}$. SKI, isolated from APR, also displayed strong inhibitory effect on phospholipase activity with an $\mathrm{IC}_{50}$ value of $51.1 \pm 3.5 \mu \mathrm{g} / \mathrm{ml}$ (Fig. 5). Due to the low $\mathrm{IC}_{50}$ concentration, it can be presumed that SKI induced the perceived bioactivity. Flavones have been found to have anti-venom activity such as that of the flavonoid extract of the root bark of Parinari curatellifolia which was indicated to offer significant protection $(p<0.05)$ against Echis carinatus venom at a dose of $237 \mathrm{mg} / \mathrm{kg}$ (Omale et al., 2012). Pure compounds such as aristolochic acid from herbal sources have been found to increase the immune response and decrease lytic and edematose action of some phospholipases of snake venoms (Gomes et al., 2010). Coumestan and steroids such as $\beta$-sitosterol and stigmasterol (derived from the methanolic root extract of Pluchea indica) circumvented lipid peroxidation and superoxide dismutase activity induced by venom inoculation (Gomes et al., 2007). Catequines, flavones, anthocyanines, and condensed tannins were observed to inhibit hemorrhage induced by Bothrops asper venom and was correlated to the chelation of the zinc in metalloproteinases (Castro et al., 1999). The leaf powder of $A$. paniculata along with other plants is traditionally used in Tamil Nadu, India as an oral concoction in envenomings (Srivastava and Pandey, 2006). In the Khamti tribe of Arunachal Pradesh, India, A. paniculata seed powder is administered orally as

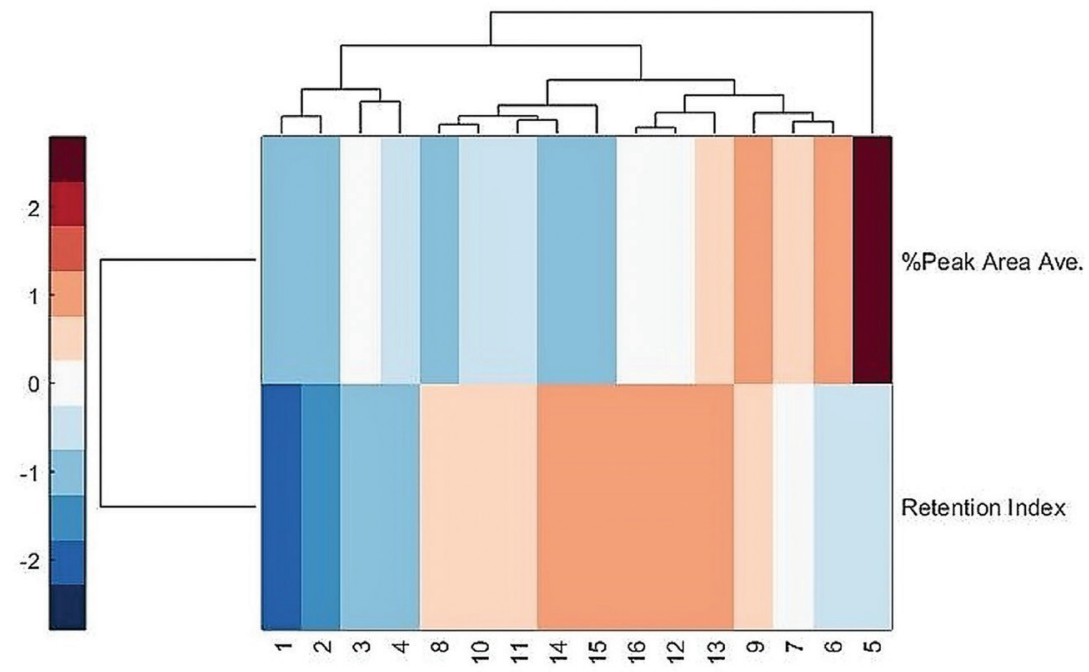

Figure 2. A hierarchically clustered heat map of the components found in dichloromethane extracts of APR. Each column represents a compound in Table 1 labeled with its corresponding peak number. Rows represent the RI and the percent peak area. 

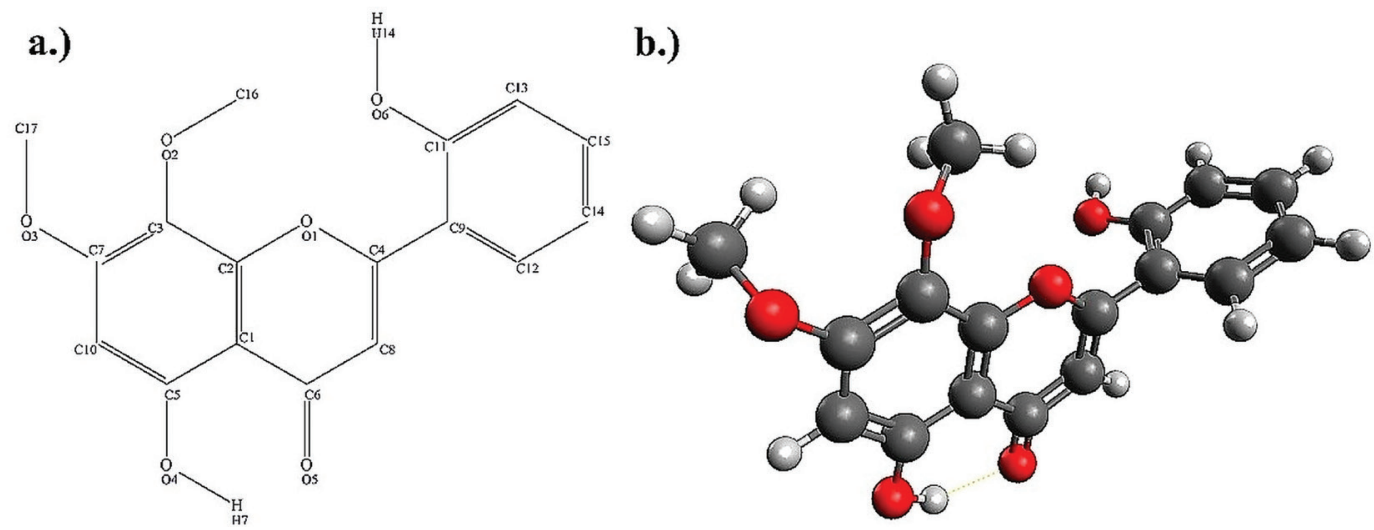

Figure 3. The chemical structure of SKI (a) with assigned atom numbers and (b) 3-D molecule.
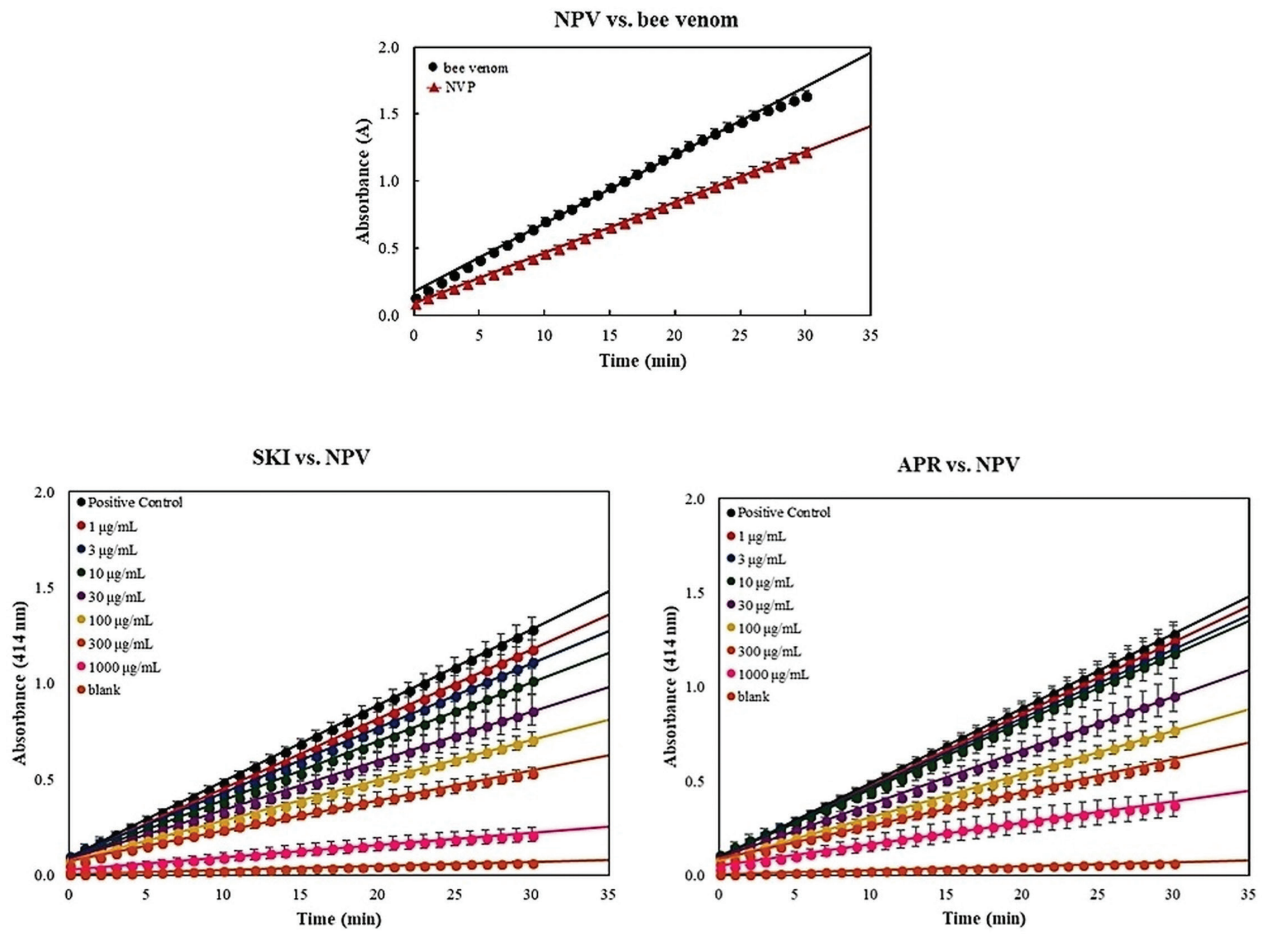

Figure 4. Absorbance measurements for: NPV versus bee venom, APR versus NPV, and SKI versus NPV monitored for 30 minutes at $\lambda=414 \mathrm{~nm}$. Linear regression analysis gave the value of change in absorbance $\left(\Delta \mathrm{A}_{414}\right)$ as the slope.

an antidote for snake bites (Das and Hui, 2006). Ethanolic extract of $A$. paniculata has been reported to exhibit anti-inflammatory activity and inhibitory/neutralizing effect on $\mathrm{SPLA}_{2}$, however, only few attempts have been done to determine the potent compound responsible for this activity (Kishore et al., 2016).

In this work, SKI and APR have shown inhibitory activities against $\mathrm{SPLA}_{2}$ although there were no previous reports of the aforementioned. We earlier reported that both APR is not cytotoxic $\left(\mathrm{IC}_{50}>100 \mathrm{mg} / \mathrm{ml}\right)$ to wild type primary human dermal neonatal fibroblasts (HDFn) (Tan et al., 2018). The snake venom neutralization by constituents of plants like $A$. paniculata roots could be the first line of defense to the attenuation of the catalytic and hydrolytic properties of snake toxins which mitigate tissue damage and increase the life expectancy.

\section{Molecular docking of SKI with PLA}

The summary of docking and cluster analysis using AutoDock 4.0 is shown in Table 2. The best candidates after the screening are the phospholipase $\mathrm{A}_{2}\left(\mathrm{PLA}_{2}\right)$ homologues. Four structures (1LN8, 1S6B, 1PSH, and 1A3F) (Berman et al., 2000) were chosen for further docking analysis and the best-docked conformation of SKI for each target is shown in Figure 6. These are all crystal structures of PLA proteins found in the venom of Napa sp. 1LN8 and 1S6B are different isoforms of PLA from Naja sagittifera. While 1LN8 was crystallized as a monomer 


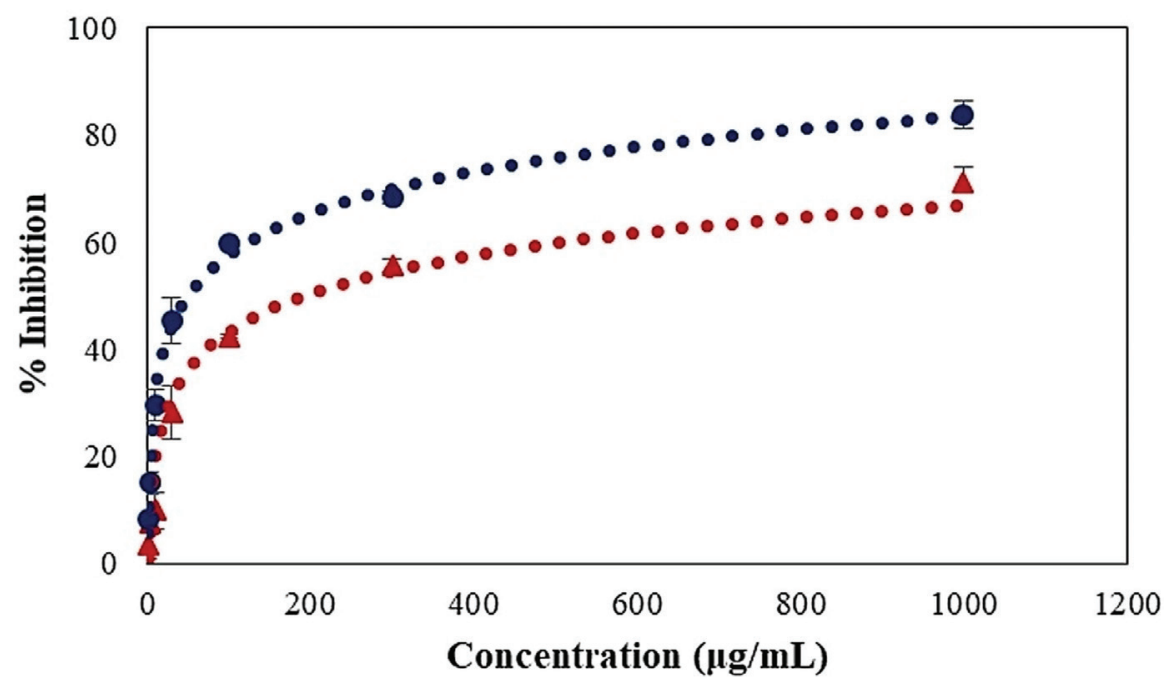

$\triangle \mathrm{APR} \bullet \mathrm{SKI}$

Figure 5. Inhibitory effect of APR and SKI against sPLA activity.

Table 2. Top three clusters of SKI conformations docked to candidate targets in Naja sp. venom.

\begin{tabular}{llcc}
\hline Species & PLA $\mathbf{2}$ homologues & No. of conformations & $\begin{array}{c}\text { Highest binding energy } \\
\text { (kcal/mol) }\end{array}$ \\
\hline \multirow{4}{*}{ Naja sagittifera } & 1LN8 & 101 & -8.72 \\
& Cluster 1 & 6 & -7.56 \\
& Cluster 2 & 14 & -7.50 \\
& Cluster 3 & & \\
& 1S6B & 16 & -7.48 \\
& Cluster 1 & 3 & -6.90 \\
Cluster 2 & 2 & -6.59 \\
Cluster 3 & & -8.58 \\
1PSH naja & Cluster 1 & 74 & -8.11 \\
& Cluster 2 & 44 & -7.86 \\
& Cluster 3 & 39 & -7.97 \\
1A3F & & -7.65 \\
& Cluster 1 & 70 & -7.61 \\
\hline
\end{tabular}

with free bound $\mathrm{Ca}^{2+}, 1 \mathrm{~S} 6 \mathrm{~B}$ was crystallized as a dimer where the bound calcium ions $\left(\mathrm{Ca}^{2+}\right)$ of the monomers are relocated from the calcium binding domain to the intermolecular space where they are supposed to be responsible for dimerization (Jabeen et al., 2005 ) and thus, the $\mathrm{Ca}^{2+}$ ions are not able to interact with a ligand. $1 \mathrm{PSH}$ and $1 \mathrm{~A} 3 \mathrm{~F}$ are the crystal structures of $\mathrm{PLA}_{2}$ from $N$. naja. $1 \mathrm{PSH}$ was crystallized with the bound $\mathrm{Ca}^{2+}$ intact, while $1 \mathrm{~A} 3 \mathrm{~F}$ was crystallized independently under $\mathrm{Ca}^{2+}$-free conditions (Fremont et al., 1993; Segelke et al., 1998). As seen in Table 2, highly negative binding energies are predicted for the binding of skullcapflavone to $\mathrm{PLA}_{2}$ proteins. The negative binding energies are due to the various non-bonding interactions of SKI with the active site residues of the four proteins. For SKI-1LN8, H14 interacted with the carbonyl carbon of Leu2 and $\mathrm{H} 7$ interacted with the carbonyl of Phe22. For SKI-1S6B, O3 interacted with the side chain $\mathrm{NH}_{3}^{+}$ of Lys64 and H14 interacted with the carbonyl of Thr2. For SKI1PSH, H14 interacted with the carbonyl of Asp148, O6 interacted with the imidazole group of His47, O4 interacted with the amino $\mathrm{H}$ of Gly31. Finally, for SKI-1A3F, H14 interacted with the carbonyl group of Gly29 and $\mathrm{O} 1$ interacted with the phenol $\mathrm{OH}$ of Tyr63. The strong non-bonding interactions between SKI and the proteins suggested that it is highly likely for SKI to inhibit PLA proteins. Thus, the observed experimental anti-venom properties of the compound could be attributed to the inhibition of PLA $\mathrm{P}_{2}$ of 


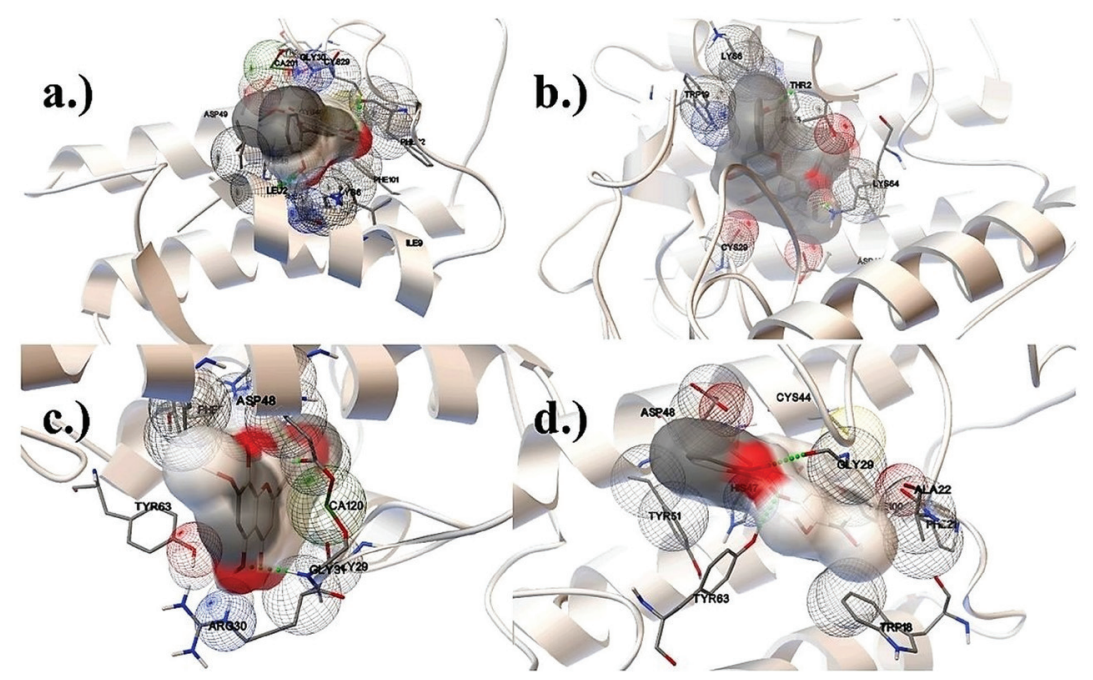

Figure 6. Optimum docked conformations of skullcapflavone, shown in licorice model superimposed with its molecular surface area, in the predicted binding site of each of the candidate target protein: (a) ILN8, (b) 1S6B, (c) 1PSH, and (d) 1A3F. The protein backbones are depicted by silver ribbon diagrams, while interaction residues are shown in licorice model. Van der Waals interactions are illustrated using wireframe spheres, while hydrogen bonds are highlighted with green dotted lines.

N. philippinensis. It is known that $\mathrm{PLA}_{2}$ are critical compounds for snake venoms, as they facilitate the lysis of cell membranes of prey cells (Gutiérrez and Lomonte, 1995). Therefore, the inhibition of $\mathrm{PLA}_{2}$ proteins can reasonably explain the decreased venomous activity of the snake venom in the presence of SKI.

From Table 2, it can be observed that proteins which contain a free bound $\mathrm{Ca}^{2+}$ (1LN8 and 1PSH) have a higher binding energy compared to proteins with no free bound $\mathrm{Ca}^{2+}(1 \mathrm{~S} 6 \mathrm{~B}$ and $1 \mathrm{~A} 3 \mathrm{~F}$ ) available to interact with the ligand. From Figure 6 , it is shown that when $\mathrm{Ca}^{2+}$ (green spheres in 1LN8 and 1PSH) are present in the binding site, it interacts with an electron rich group, i.e., oxygen, of the SKI. In addition, to the nonbonding interactions mentioned, it is possible that the ion-dipole interaction between SKI and $\mathrm{Ca}^{2}$ contributed to the higher binding energy in 1LN8 and 1PSH. This indicated that the presence of bound $\mathrm{Ca}^{2+}$ is important in the binding of the compound to PLA 2 proteins.

\section{CONCLUSION}

In summation, NPV SPLA $_{2}$ activity was confirmed with a calculated activity of $0.0796 \pm 0.0018 \mu \mathrm{mol} / \mathrm{minutes} / \mathrm{ml}$ compared with bee venom sPLA activity of $0.1074 \pm 0.0031$ $\mu \mathrm{mol} / \mathrm{minutes} / \mathrm{ml}$. This was typical for venoms extracted from related Naja species (Omale et al., 2012). Antivenom activity was proved through the inhibition of $\mathrm{SPLA}_{2}$ activity by APR $\left(\mathrm{IC}_{50}\right.$ : $192.7 \pm 10.9 \mu \mathrm{g} / \mathrm{ml})$ and SKI isolated from APR $\left(\mathrm{IC}_{50}: 51.1 \pm 3.5\right.$ $\mu \mathrm{g} / \mathrm{ml})$. SKI had a lower $\mathrm{IC}_{50}$ suggesting that SKI was the active component of APR's anti-venom effects. Further molecular docking analysis showed highly negative binding energies for the binding of SKI to PLA 2 proteins which suggested the inhibitory potential of SKI. An interesting observation was that proteins which contain a free bound $\mathrm{Ca}^{2+}$ have a more negative binding energy compared with proteins without a free bound $\mathrm{Ca}^{2+}$. It was shown that when $\mathrm{Ca}^{2+}$ is present in the binding site, it interacts with electron rich groups in SKI. We previously reported that APR is not cytotoxic
$\left(\mathrm{IC}_{50}>100 \mathrm{mg} / \mathrm{ml}\right)$ to wild type HDFn (Tan et al., 2018). The NPV neutralization by constituents of APR, which was found to be rich in phytosterols and methoxylated flavones as deduced from GC-EI-MS analyses, was found to be promising and could be a start of the deeper understanding of the anti-venom properties of APR.

\section{ACKNOWLEDGMENTS}

A research grant from De La Salle University Science Foundation, through the University Research Coordination Office, is gratefully acknowledged. The authors are also grateful to Professor Michio Murata of the Department of Chemistry, Graduate School of Science, Osaka University.

\section{REFERENCES}

Berman HM, Westbrook J, Feng Z, Gilliland G, Bhat TN, Weissig H, Shindyalov IN, Philip E, Bourne PE. The protein data bank Nucleic Acids Res, 2000; 28(1):235-42.

Brunda G, Sashidhar RB. Epidemiological profile of snake-bite cases from Andhra Pradesh using immunoanalytical approach. Indian J Med Res, 2007; 125(5):661-8.

Castro O, Gutierrez JM, Barrios M, Castro I, Romero M, Umana E. Neutralization of the hemorrhagic effect induced by Bothrops asper (Serpentes: Viperidae) venom with tropical plant extracts. Rev Biol Trop, 1999; 47(3):605-16.

Chao W-W, Lin B-F. Isolation and identification of bioactive compounds in Andrographis paniculata (Chuanxinlian). Chin Med, 2010; 5:17; doi:10.1186/1749-8546-5-17.

Chippaux JP. Snakebite envenomation turns again into a neglected tropical disease! J Venom Anim Toxins Incl Trop Dis, 2017; 23:38.

Das AK, Hui T. Ethnomedicinal studies of the Khamti tribe of Arunachal Pradesh. Indian J Tradit Knowl, 2006; 5(3):317-22.

Fatima L, Fatah C. Pathophysiological and pharmacological effects of snake venom components: molecular targets. J Clin Toxicol, 2014; 4:2; doi:10.4172/2161-0495.1000190.

Fremont DH, Anderson DH, Wilson IA, Dennis EA, Xuong NH. Crystal structure of phospholipase A2 from Indian cobra reveals a trimeric 
association. Proc Natl Acad Sci USA, 1993; 90:342-46; doi:10.1073/ pnas.90.1.342.

Gomes A, Das R, Sarkhel S, Mishra R, Mukherjee S, Bhattacharya S, Gomes A. Herbs and herbal constituents active against snake bite. Indian J Exp Biol, 2010; 48(9):865-78.

Gomes A, Saha A, Chatterjee I, Chakravarty AK. Viper and cobra venom neutralization by $\beta$-sitosterol and stigmasterol isolated from the root extract of Pluchea indica Less. (Asteraceae). Phytomedicine, 2007; 28:14(9):637-43; doi:10.1016/j.phymed.2006.12.020.

Gopi K, Renu K, Jayaraman G. Inhibition of Naja naja venom enzymes by the methanolic extract of Leucas aspera and its chemical profile by GC-MS. Toxicol Rep, 2014; 1:667-73; doi:10.1016/J. TOXREP.2014.08.012

Gupta S, Choudhry MA, Yadava JNS, Srivastava V, Tandon JS. Antidiarrhoeal activity of diterpenes of andrographis paniculata (kal-megh) against escherichia coli enterotoxin in in vivo models. Pharm Biol, 1990; 28(4): 273-83; doi:10.3109/13880209009082833.

Gutiérrez J, Lomonte B. Phospholipase A2 myotoxins from Bothrops snake venoms. Toxicon, 1995; 33(11):1405-24.

Gutiérrez JM, Calvete JJ, Habib AG, Harrison RA, Williams DJ, Warrell DA. Snakebite envenoming. Nat Rev Dis Prim, 2017; 3:17063; doi:10.1038/nrdp.2017.63.0

Hauert J, Marie M, Sussmann A, Bargetzi JP. The major lethal neurotoxin of the venom of Naja naja philippinensis. Chem Biol Drug Design, 1974; 6(4):201-22.

Jabeen T, Sharma S, Singh N, Singh RK, Kaur P, Perbandt M, Betsel Ch, Srinivasan A, Singh TP. Proteins struct. Funct Bioinforma, 2005; 59(4):856-63; doi:10.1002/prot.20464.

Kishore V, Yarla N, Zameer F, Prasad MN, Santosh MS, More SS, Rao DG, Dhananjaya BL. Inhibition of group IIA secretory phospholipase $\mathrm{A}_{2}$ and its inflammatory reactions in mice by ethanolic extract of Andrographis paniculata, a well-known medicinal food. Pharmacogn Res, 2016; 8(3):213.

Moon JY, Jung HJ, Moon MH, Chung BC, Choi MH. Heat-map visualization of gas chromatography-mass spectrometry based quantitative signatures on steroid metabolism. J Am Soc Mass Spectrom, 2009; 20(9):1626-37; doi:10.1016/j.jasms.2009.04.020.

Morris GM, Ruth H, Lindstrom W, Sanner MF, Belew RK, Goodsell DS, Olson AJ. Software news and updates AutoDock4 and AutoDockTools4: Automated docking with selective receptor flexibility. J Comput Chem, 2009; 30:2785-91; doi:10.1002/jcc.21256.

Naeem SM. Snake venom toxins. J Saidu Med Coll, 2017;
Omale S, Auta A, Amagon KI, Ighagbon MV. Anti-snake venom activity of flavonoids from the root bark extract of Parinari curatellifolia in Mice. Int J Pharm Res, 2012; 4(2):55-8.

Ragasa C, De Los Santos A, Rideout J. An antimicrobial and cytotoxic labdane diterpene from Andrographis paniculata ACQUIRE Repository 6.3.SP2. ACGC Chem Res Commun, 2008; 22:44-8. Available via http://acquire.cqu.edu.au:8080/vital/access/manager/Repository/ cqu:4219 (Accessed 6 July 2018).

Segelke BW, Nguyen D, Chee R, Xuong NH, Dennis E. Structures of two novel crystal forms of Naja naja naja phospholipase A2 lacking Ca2+ reveal trimeric packing. J Mol Biol, 1998; 279:223-32; doi:10.1006/jmbi.1998.1759.

Soares AM, Ticli FK, Marcussi S, Lourenço MV, Januário AH, Sampaio SV, Giglio JR, Lomonte B, Pereira PS. Medicinal plants with inhibitory properties against snake venoms. Curr Med Chem, 2005; 12:2625-41; doi:10.2174/092986705774370655.

Srivastava S, Pandey H. Traditional knowledge for Agroecosystem management. Indian J Tradit Knowl, 2006; 5(1):121-31.

Tan MCS, Oyong GG, Shen CC, Ragasa CY. Chemical constituents of andrographis paniculata (Burm.f.) nees. Int J Pharmacogn Phytochem Res, 2016; 8(8):1398-402.

Tan MC, Oyong G, Shen C-C, Ragasa C. Cytotoxic activities of the dichloromethane extracts from Andrographis paniculata (Burm. f.) nees. J Nat Sci Biol Med, 2018; 9(2):201.

Trott O, Olson AJ. AutoDock Vina: improving the speed and accuracy of docking with a new scoring function, efficient optimization, and multithreading. J Comput Chem, 2009; 31(2):455-61; doi:10.1002/ jec. 21334 .

How to cite this article:

Tan MCS, Malabed RS, Franco FC, Reyes YIA, Tan DS, Oyong GG, Shen C-C, Ragasa CY. The anti-venom potential of Andrographis paniculata (Burm.f.) Nees roots and its constituent skullcapflavone I. J Appl Pharm Sci, 2019; 9(03):073-081. 7(1):1-3. 